\title{
Tsunami Folklore and Possible Tsunami Source on the Eastern Coast of Taiwan
}

\author{
Masataka Ando ${ }^{1, *}$, Mamoru Nakamura ${ }^{2}$, and Cheng-Horng Lin ${ }^{1}$ \\ ${ }^{1}$ Institute of Earth Sciences, Academia Sinica, Taipei, Taiwan \\ ${ }^{2}$ Department of Geosciences, University of Ryukyus, Okinawa, Japan
}

Received 1 February 2013, accepted 12 July 2013

\begin{abstract}
Folklore tells of a large sea wave that struck an area of Chenggong on the eastern coast of Taiwan. This event is estimated to have occurred in the middle of the $19^{\text {th }}$ century based on an oral history of the area. Despite an estimated run-up height of more than $18 \mathrm{~m}$, no other folklore related to a tsunami has been found in areas adjacent to the site for several reasons. Considering the importance of understanding the dangers posed to the eastern coast of Taiwan, numerical tsunami simulations were carried out to study localized amplification effects. Three tsunami sources were studied: (1) the westernmost portion of the Ryukyu trench, (2) offshore of Chenggong and (3) the source of the 1771 Yaeyama tsunami along the Ryukyu trench. Numerical simulations using detailed bathymetric maps reveal that possible tsunami waves are not significantly amplified around Chenggong; the eastern coast of Taiwan should have been affected by the $19^{\text {th }}$ century tsunami if it was large enough. This study emphasizes the importance of investigation of paleo-tsunamis along the eastern coast of Taiwan to assess the risk for future tsunami hazards.
\end{abstract}

Key words: Folklore, Malaulau, Eastern coast of Taiwan, Tsunami simulation

Citation: Ando, M., M. Nakamura, and C. H. Lin, 2013: Tsunami folklore and possible tsunami source on the eastern coast of Taiwan. Terr. Atmos. Ocean. Sci., 24, 951-961, doi: 10.3319/TAO.2013.07.12.01(T)

\section{INTRODUCTION}

Taiwan is located at the convergence of the Eurasian and Philippine Sea Plates (Fig. 1). It is a complex boundary due to the presence of two migrating subduction zones with opposing polarities (Suppe 1981; Blanchet et al. 1986; Lin 2000), with a convergence rate of approximately $80 \mathrm{~mm} \mathrm{yr}^{-1}$ or more ( $\mathrm{Yu}$ et al. 1997; Hsu et al. 2009). In Taiwan, records of earthquakes and tsunamis can be traced back to the $17^{\text {th }}$ century (e.g., Hsu 1983; Cheng and Yeh 1989; Ng et al. 2009). A brief description of historical earthquakes by Cheng and Yeh (1989) is available at the website of the Central Weather Bureau (CWB) (http://www.cwb.gov.tw/ V7/earthquake/damage_eq.htm). In addition, tsunami catalogs have been summarized by Yü (1981) and Hsu and Lee (1996). Based on historical documents, Ma and Lee (1997) calculated numerical simulations of tsunamis caused by large earthquakes around Taiwan. Recently, Mak and Chan (2007) and Lau et al. (2010) revised historical tsunami data-

\footnotetext{
* Corresponding author

E-mail:ando@earth.sinica.edu.tw
}

bases for Taiwan and the South China Sea using numerous historical documents in which several tsunamis were reported as causing more than several fatalities in Taiwan. After the mid- $18^{\text {th }}$ century, the wave events in 1781 in southern Taiwan and in 1878 off northern Taiwan are associated with large tsunamis. The 1781 event is thought to be related to the subduction of the Manila trench. The tsunami along the Manila trench has been modeled by Megawati et al. (2009), Wu and Huang (2009) and Okal et al. (2011). The 18 December 1867 tsunami is the first event that was relatively well documented in terms of its date and its damage on land. Although it is estimated to have been a medium-size tsunami (Ma and Lee 1997), it has not been interpreted tectonically.

No large tsunamis are thought to have struck the eastern coast of Taiwan because the seafloor depth increases to $500 \mathrm{~m}$ within of $3-5 \mathrm{~km}$ of the coast. Folklore of the Ami, one of the Taiwanese aboriginal tribes, says that "a big sea wave struck the area, then plants and trees all perished, and afterwards the place was named as Malaulau" (Abe 1938); "Malaulau" means "withered" and is located at the center 


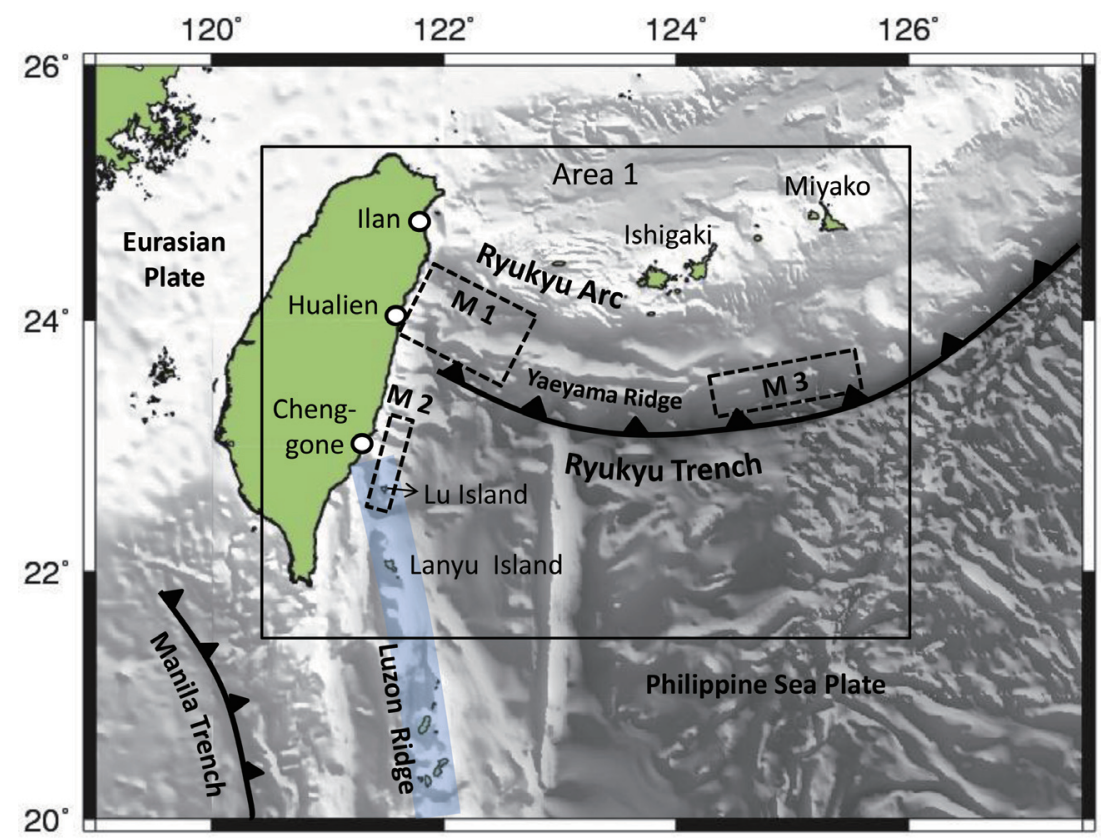

Fig. 1. Bathymetric map surrounding Taiwan. The three rectangles depict the tsunami sources used in this study: Model 1 (M1) - the westernmost Ryukyu trench fault segment (Hsu et al. 2012), Model 2 (M2) - a back-thrust of the Manila trench subduction (Lin et al. 2009) and Model 3 (M3) the 1771 Yaeyama tsunami source (Nakamura 2009). The large rectangle shows the numerical simulation area of Area 1 used in Figs. 3,5 and 7.

of Chenggong on the eastern coast of Taiwan (Fig. 2). The Malaulau tsunami had a run-up of at least $18 \mathrm{~m}$ above sea level (a. s. 1.) $400 \mathrm{~m}$ inland from the coast. There are a number of stories or folklore by Taiwanese tribes related to large sea waves on the eastern coast. To investigate the possible Malaulau tsunami, Matta et al. (2013a) collected soil samples to find evidence for paleo-tsunamis and identified three sedimentary layers that may have been caused by tsunamis. The first event occurred between 2800 and 2500 cal yrs BP, the second event between 2340 and $2150 \mathrm{cal}$ yrs BP and the third event between 650 - $790 \mathrm{cal}$ yrs BP and the present. The Malaulau event falls within the time range for the third event. In addition, several large boulders on a beach may have been transported by one or more tsunamis in southeastern Taiwan (Matta et al. 2013b), although the "tsunami boulders" are not definitely related to the possible Malaulau tsunami.

The occurrence of the Malaulau tsunami is not yet confirmed. If the tsunami was generated by an offshore source larger than a certain size, it should have struck the entire eastern coast of Taiwan. Similar folklore about the tsunami may exist in areas outside of Chenggong. Because of the importance of understanding dangers posed to the eastern coast, we have conducted a numerical simulation of tsunamis to determine if Chenggong has strong local amplification effects and understand the tsunami hazards for the eastern coast of Taiwan.

\section{MALAULAU FOLKLORE}

The location name of "Malaulau" in Chenggong was first reported by Abe (1938), who interviewed local resi- dents to investigate the origin of locality names in Taiwan. Chenggong was originally inhabited by the Ami who arrived in this locality between the middle of the $18^{\text {th }}$ century and the middle of the $19^{\text {th }}$ century; they typically dwelled at the base of mountains (Ceng-Sheng Yuan, personal communication, June 14, 2009). The location "Malaulau" is briefly mentioned in Abe's report of the tsunami which affected cultivated land at Chenggong 80 - 90 years prior to the publication of his book and suggests the Malaulau event occurred in the middle of $19^{\text {th }}$ century. In the language of the Ami, ma is a prefix and laulau means "withered", which may be related to an event that happened in the area. The Malaulau site is on the fourth level of Holocene terraces a. s. 1. (Fig. 2; Yamaguchi and Ota 2002).

However, the Amis in Hualien, $100 \mathrm{~km}$ north of Chenggong, are not known to have possessed folklore about this tsunami. The absence of a story related to the tsunami in areas adjacent to Malaulau could be caused by a number of reasons, such as that the tsunami was amplified at Chenggong only due to local topographic effects or that Ami tribes lived at the base of mountains at that time which may have caused the tsunami to not have been recorded elsewhere.

The word "Malaulau" is not commonly used now in Chenggong, although Mr. He-Sheng Wang, a local historian with Chinese roots who has inhabited the area since the 1930s, reported in 2008 that he recalled hearing about Malaulau as a child. He often visited his friends in an Ami community after elementary school and listened to stories of the elder Amis, who passed their legends down to younger generations. Because the original Taiwanese tribes did not 


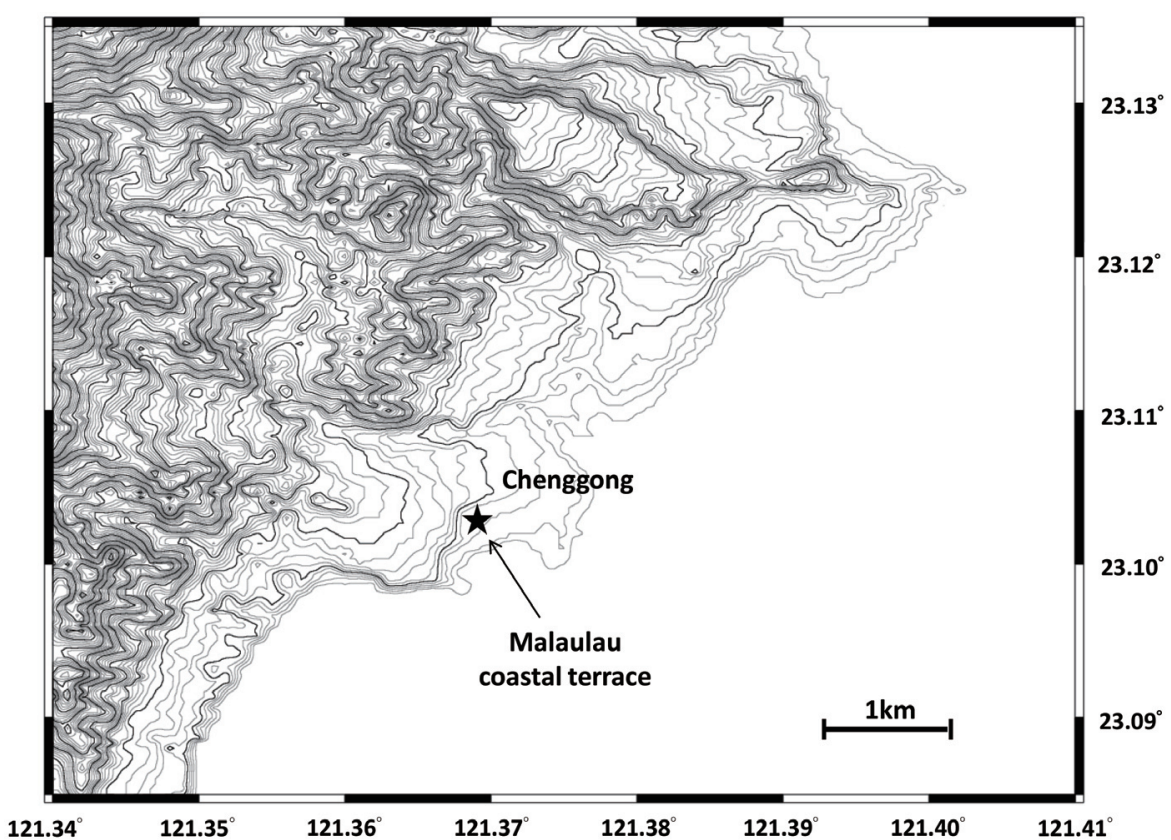

Fig. 2. Chenggong and its surroundings. The Malaulau site (the star) is located on the fourth terrace at $18 \mathrm{~m}$ a. $\mathrm{s} .1$. and $400 \mathrm{~m}$ inland from the coast. Contours based on the 40-m grid data provided by the Center for Space and Remote Sensing Research of National Central University are spaced every $5 \mathrm{~m}$.

have written text, legends were passed down orally from generation to generation. Based on information Mr. Wang provided, he estimated that the event occurred in the middle of $19^{\text {th }}$ century, which is consistent with Abe (1938).

\section{TSUNAMI NUMERICAL SIMULATION}

Off the coast of Chenggong, there are some bathymetrical highs and irregularities, (Fig. 1), where the volcanic Luzon Ridge extends northwards from Luzon Island and meets the coast of Taiwan near Chenggong (Fig.1). These bathymetric features may modify an incoming tsunami. We attempt to simulate a tsunami using two available bathymetric maps.

In the simulations of tsunami propagation, two grid sizes are adopted. The first grid (Area 1) has a 250-m grid size, downsized from the $500-\mathrm{m}$ grid data provided by the Ocean Data Bank (ODB), and covers $21.5^{\circ}$ to $25.5^{\circ} \mathrm{N}$ latitude and $120.5^{\circ}$ to $125.0^{\circ} \mathrm{E}$ longitude (Fig. 1). For the area east of $125.0^{\circ}$, we add data from the ETOPO1 One ArcMinute Global Relief Model. The second area (Area 2) is a $9 \times 9 \mathrm{~km}$ square covering the coast and surrounding area and its origin (the left bottom corner) is located at $23.05^{\circ} \mathrm{N}$ and $121.33^{\circ} \mathrm{E}$ (the square around Chenggong in Fig. 3). For Area 2, data from Chart No. 0348A nautical map published by the Naval Meteorological and Oceanographic Office of R.O.C. in 2007 are used, with a grid resolution of $30 \mathrm{~m}$. The bathymetry in Area 2 is shallower than $100 \mathrm{~m}$. The two areas are dynamically coupled in the numerical models.

In the deep-water region, the tsunami wave height is lower than $10 \mathrm{~m}$, which is much smaller than the water depth. The nonlinear long wave equations, including nonlinear advection and bottom friction, are applied to Area 1 [Eqs. (1) - (2) in Appendix]. When a tsunami enters into the shallower near-shore regions, the water depth is reduced and the wave amplitude increases. Consequently, it is necessary to include the nonlinear dispersive equations which affect the wave dynamics [Eqs. (3) - (4) in Appendix].

The numerical method adopts the leap-frog implicit differential method to solve dispersive shallow water equations in Cartesian coordinates (Nakamura 2006). For smoothly continuous grid boundaries, we perform the simulations from far-coastal to onshore regions. For Area 2, our calculation includes the inundation of sea water by moving shorelines to allow the calculation of a wave moving onshore and withdrawing from the initial shoreline.

\section{TSUNAMI SOURCES}

This study focuses on the amplification effects of shallow bathymetry off the coast of Chenggong with respect to incoming tsunamis. For this purpose, we tentatively choose two cases: a medium-distance (100 - $200 \mathrm{~km})$ and a nearby $(30 \mathrm{~km})$ source. We examine the possibility that the Malaulau event was related to the 1771 tsunami south of Ishigaki Island, Ryukyus, which is the only well documented tsunami over the past 250 years in this region and decades earlier than the Malaulau event is thought to have occurred. For simplicity, we assume these tsunamis are caused by seismically active faults. The fault parameters of the three models are summarized in Table 1. 

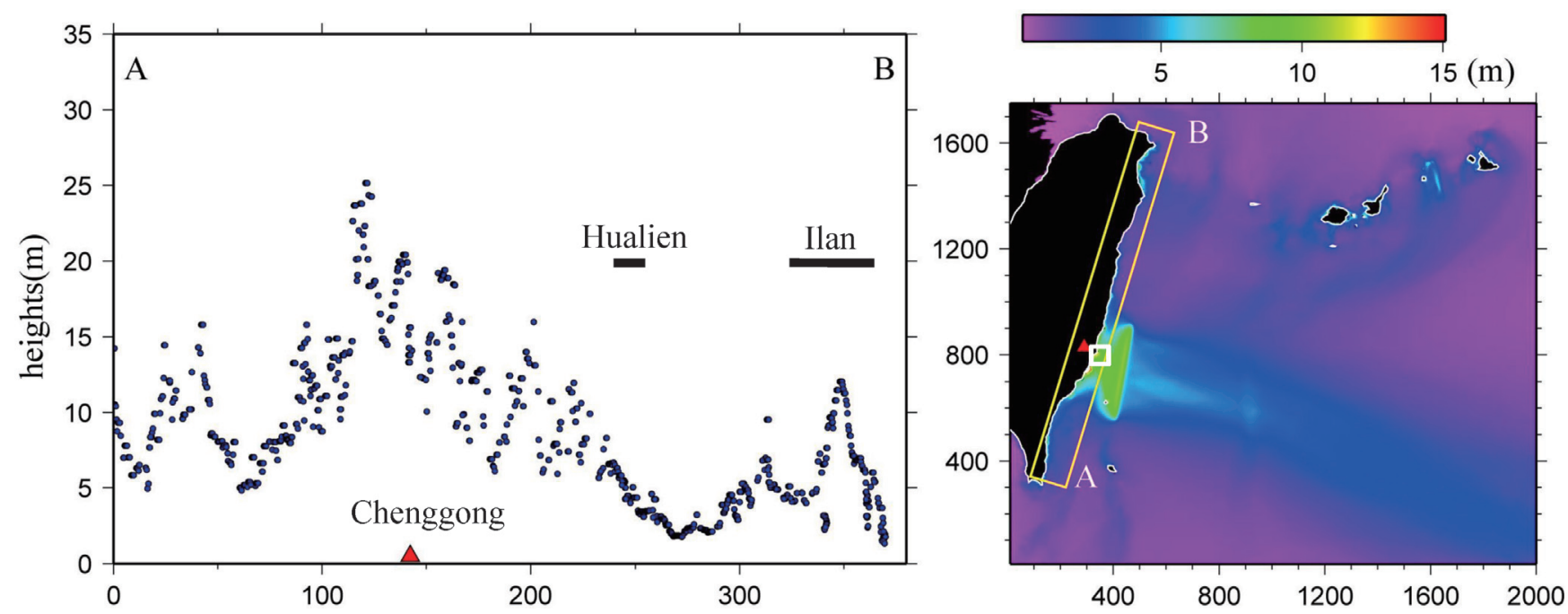

Fig. 3. The maximum tsunami height at each coastal grid point within the box A - B (top) and at each sea-bottom grid point (bottom), calculated from Model 1 for times of 0 to $3600 \mathrm{~s}$ for Area 1 with a grid interval of $250 \mathrm{~m}$ and using non-linear wave equations. The numerals on the frame are grid numbers counted from the southwestern corner. The small white square depicts Area 2, in which the nonlinear dispersive wave equations are used. The tsunami heights are given in the color bar. High amplitudes $(>20 \mathrm{~m})$ are seen on the coasts of the Ilan plain and Hualien and the area south of Chenggong. Approximate locations of the Ilan plain and Hualien are shown with thick solid lines. The straight line off the coast of Ilan depicts a large uplift corresponding to the upper edge of the fault plane. Large tsunami waves are also observed on the Lanyu and Lu Islands, southeast of Taiwan Island, and Ishigaki and Miyako Islands along the Ryukyu trench.

Table 1. Fault parameters for the three models used in this study.

\begin{tabular}{|c|c|c|c|c|c|c|c|c|c|}
\hline & \multicolumn{3}{|c|}{ Location of the center of the upper edge of the fault } & \multirow[b]{2}{*}{ Strike $\left(^{\circ}\right)$} & \multirow[b]{2}{*}{ Dip $\left({ }^{\circ}\right)$} & \multirow[b]{2}{*}{ length $(\mathbf{k m})$} & \multirow[b]{2}{*}{ width $(\mathbf{k m})$} & \multirow[b]{2}{*}{ slip (m) } & \multirow[b]{2}{*}{ Rake $\left(^{\circ}\right)$} \\
\hline & Latitude $\left({ }^{\circ}\right)$ & Longitude $\left(^{\circ}\right)$ & depth $(\mathbf{k m})$ & & & & & & \\
\hline Model 1 & 23.14 & 122.11 & 5 & 290 & 10 & 120 & 70 & 46 & 90 \\
\hline Model 2 & 22.44 & 121.68 & 5 & 190 & 30 & 100 & 50 & 20 & 90 \\
\hline Model 3 & 23.07 & 124.66 & 5 & 260 & 10 & 150 & 50 & 16 & 155 \\
\hline
\end{tabular}

Note: The geometry of Model 1 is derived from Hsu et al. (2012) and Model 3 from the geometry and fault slip from Nakamura (2009), and Model 2 given in this study.

Because the Malaulau site is located at a terrace $18 \mathrm{~m}$ a. s. 1., the run-up height should have exceeded this level. Based on numerous observations of the inundation and runup height distribution for the 2011 Tohoku-Oki earthquake (http://www.coastal.jp/tsunami2011/, Mori et al. 2011), runup heights are generally $1.5-2.0$ times higher than the inundation heights in the surrounding areas. Considering these empirical relations, we assume that the tsunami inundation height on the Chenggong shore was approximately $15 \mathrm{~m}$.

The vertical displacement of the ocean floor is calculated by a fault model with a given length, width, depth, dip angle, rake and slip using a dislocation model (Mansinha and Smylie 1971). We assume that the change in sea height mimics the seafloor deformation beneath it. This assumption is valid if the deformation area is large and the vertical displacement is small compared with the water depth (Kajiura 1970). This is generally acceptable because the water above the seafloor deformation cannot flow rapidly.

\subsection{Model 1}

As a medium-distance source, the coupled-plate zone west of the Ryukyu subduction zone (Hsu et al. 2012) is used. This source is derived by analyzing onshore GPS velocity vectors along the eastern coast of Taiwan. The GPS vectors point northwestward with an average velocity of $8.4 \mathrm{~cm} \mathrm{yr}^{-1}$ south of $23.5^{\circ} \mathrm{N}$ (Hsu et al. 2009), and gradually decrease to the north. The decrease in GPS velocity is caused by the change in plate convergence mode between the Philippine Sea and Eurasian Plates from collision to subduction at approximately $23.5^{\circ} \mathrm{N}$ (Wu et al. 2009; Hsu et al. 2012). The plate convergence rate is estimated to be $87 \mathrm{~mm} \mathrm{yr}^{-1}$, resulting in a large slip deficit at the plate interface. $\mathrm{Nev}$ ertheless, no historical earthquake has occurred in this segment in the last several hundred years.

\subsection{Model 2}

The back-thrust of the Manila trench (Lin et al. 2009) 
is chosen as a nearby source. In general, fold and thrust belts can form within the overriding plate at subduction margins (Davis et al. 1983) in association with plate convergence. Outside of accretionary wedges, back-thrusts antithetic to the subduction thrust form, releasing accumulated strain caused by subduction. The Manila trench back-thrust lies in the eastern margin of the accretionary wedge and consists of westward-dipping thrust faults (Lundberg et al. 1997 ; Shyu et al. 2005; Chi and Reed 2008; Lin et al. 2009). There is currently little seismicity along the back-thrust, but we assume thrusting along the boundary.

\subsection{Model 3}

In 1771, a large tsunami struck Ishigaki and Miyako Islands in the western Ryukyu subduction zone, with a runup height of up to $30-35 \mathrm{~m}$. A number of studies have been carried out on this tsunami based on historical documents and tsunami boulders (e.g., Imamura 1938; Makino 1968; Kato and Kimura 1983; Nakata and Kawana 1995). The source of this tsunami was inferred to be a tsunami earthquake with $\mathrm{M}_{\mathrm{w}}=8.0$ near the trench axis (Nakamura 2009) based on huge tsunami heights with relatively weak ground motions on the islands recorded in historical documents. Contrastingly, a model of a submarine landslide and simultaneous intra-slab faulting was proposed by Goto et al.

(a)

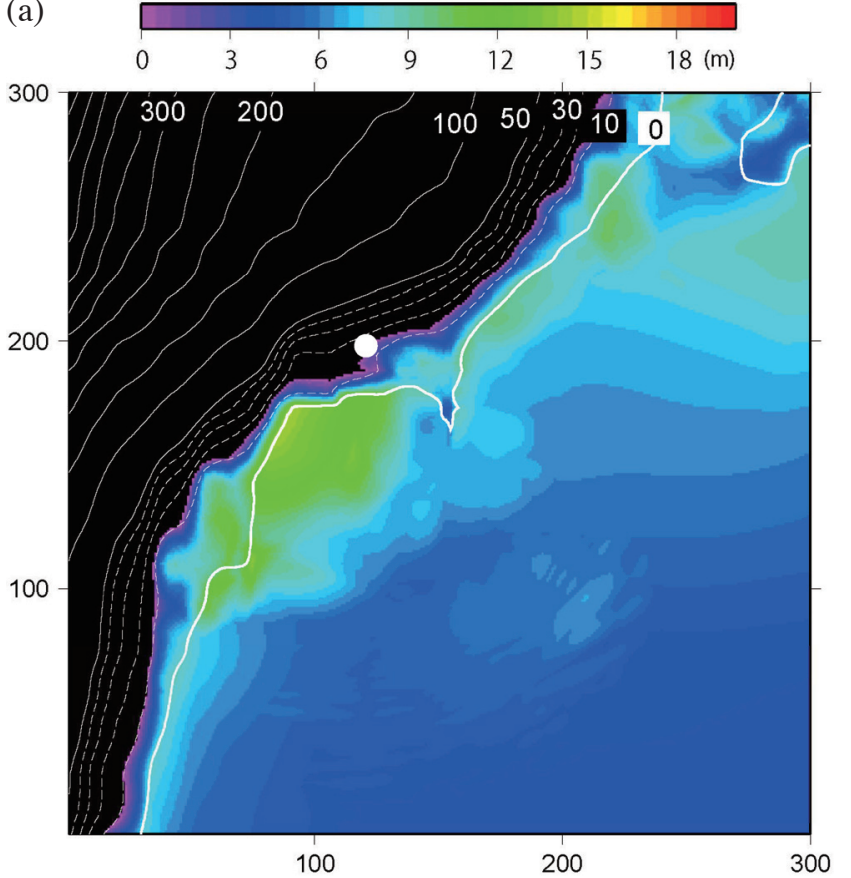

(2010). Considering the distribution of high tsunami waves over Ishigaki and Miyako Islands, we adopt the model of an inter-plate thrust earthquake by Nakamura (2009) and use his fault geometry and parameters. For this calculation, we focus on the possibility that the 1771 tsunami was the event described in the Malaulau story.

\section{RESULTS AND DISCUSSION}

Figures 3 through 8 show results for the three models, depicting the maximum coast and sea surface heights from times 0 to $3600 \mathrm{~s}$.

\subsection{Model 1}

Figure 3 shows the maximum wave height on the coast within the box A - B (top) and at each seafloor point (bottom). In this case, because the rake angle is $155^{\circ}$, the ratio of the strike slip component to the dip slip component is 2.2. Consequently the fault slip of $46 \mathrm{~m}$ is necessary to produce large vertical deformation, which can generate a tsunami height of $15 \mathrm{~m}$ on the shore of Chenggong. The initial deformation is seen as a rectangle in the figure (Fig. 3 bottom). High tsunami amplitudes (15-27 m) can be seen around the bathymetric bumps around the northern extension of the Luzon ridge over a range of $50 \mathrm{~km}$ south of Chenggong (Fig. 3

(b)

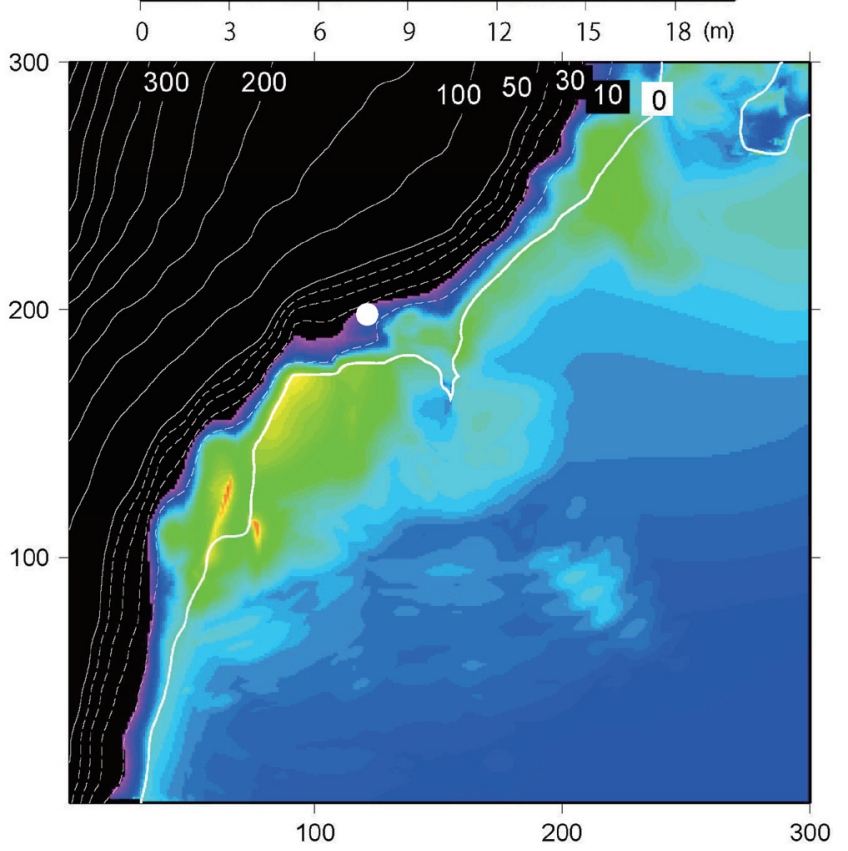

Fig. 4. (a) The maximum tsunami height at each grid point calculated for Model 1 from times 0 to $3600 \mathrm{~s} \mathrm{in} \mathrm{Area} \mathrm{2,} \mathrm{where} \mathrm{the} \mathrm{grid} \mathrm{interval} \mathrm{is} 30 \mathrm{~m}$ and non-linear dispersive wave equations are used. The numerals on the frame are grid numbers counted from the southwestern corner. The tsunami heights are given in the color bar. The tsunami is allowed to flow onshore in the calculation. The onshore tsunami heights indicate the depth to the underlying land. The Malaulau site (the white solid circle) is generally covered by the tsunami. (b) The same as in Fig. 4a, except using non-linear long-wave equations. The onshore and near-shore tsunami height is somewhat higher than that for the dispersive results shown in Fig. 4a. The Malaulau site (white solid circle) is covered by the tsunami. 


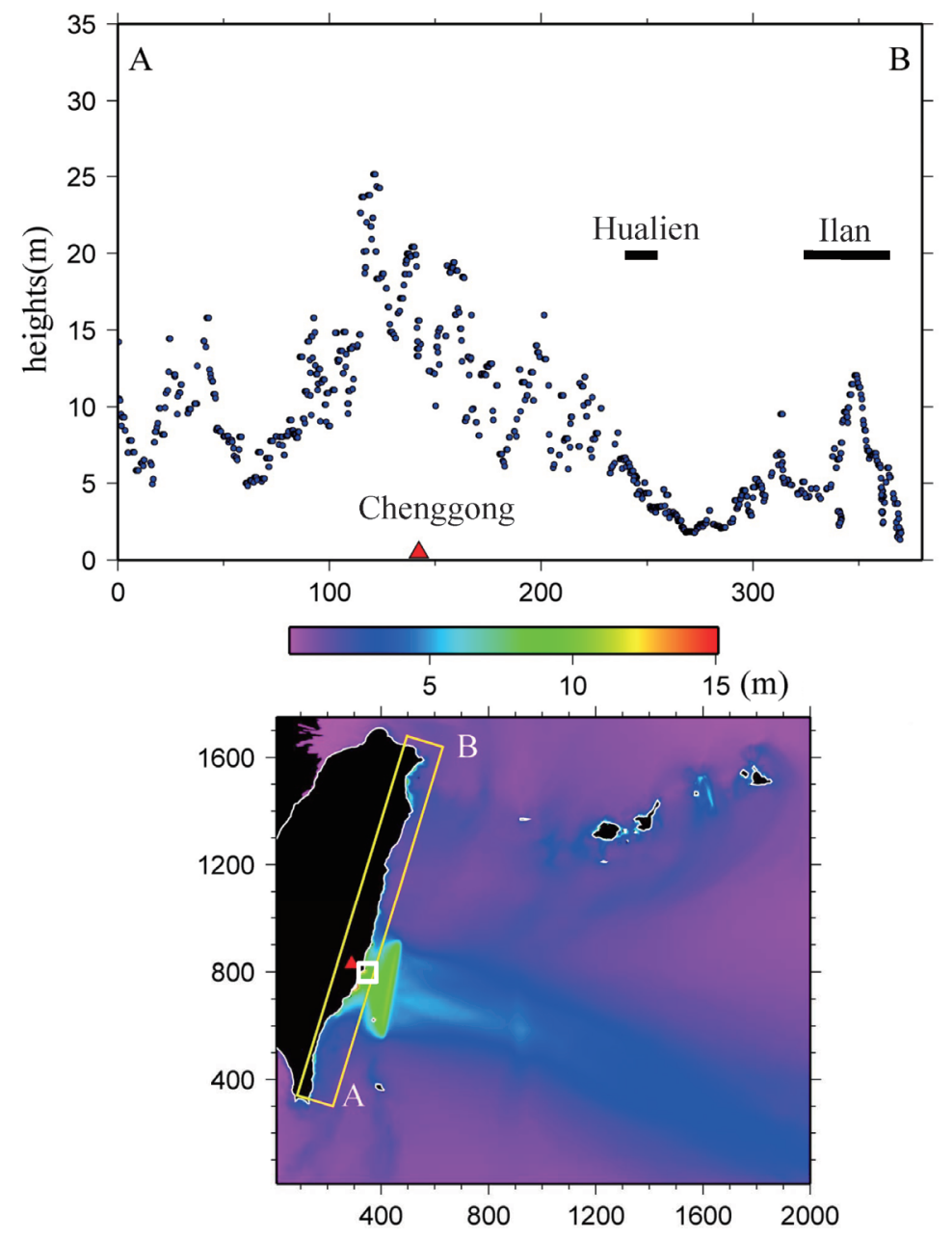

Fig. 5. The same as in Fig. 3, except for the tsunami in Model 2. Large amplitude waves (>18 m) are observed south of Chenggong. The straight line off the coast of Chenggong depicts the large uplift corresponding to the upper edge of the fault plane.

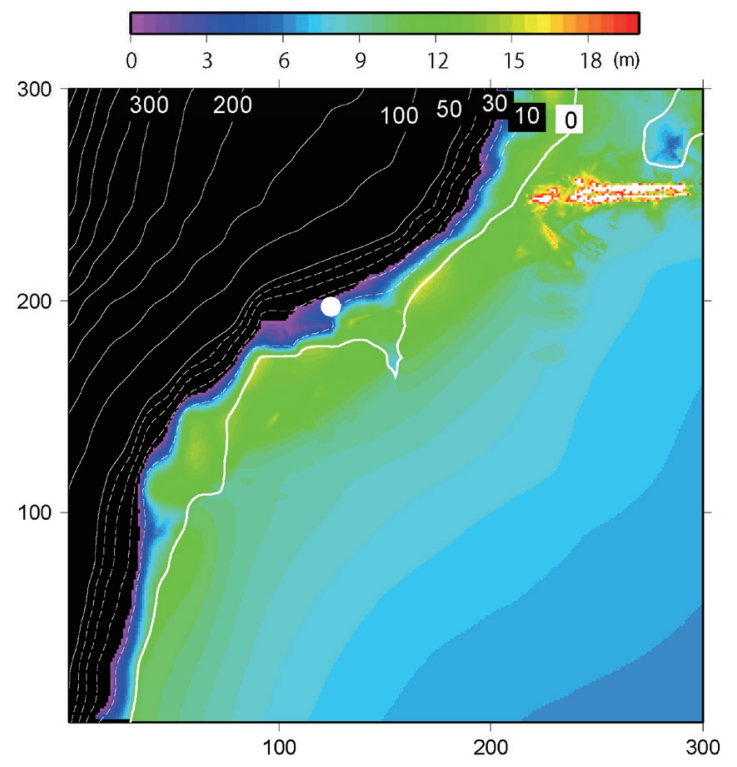

Fig. 6. The same as in Fig. 4a except for the tsunami in Model 2. The Malaulau site (white solid circle) is generally covered by the tsunami. 


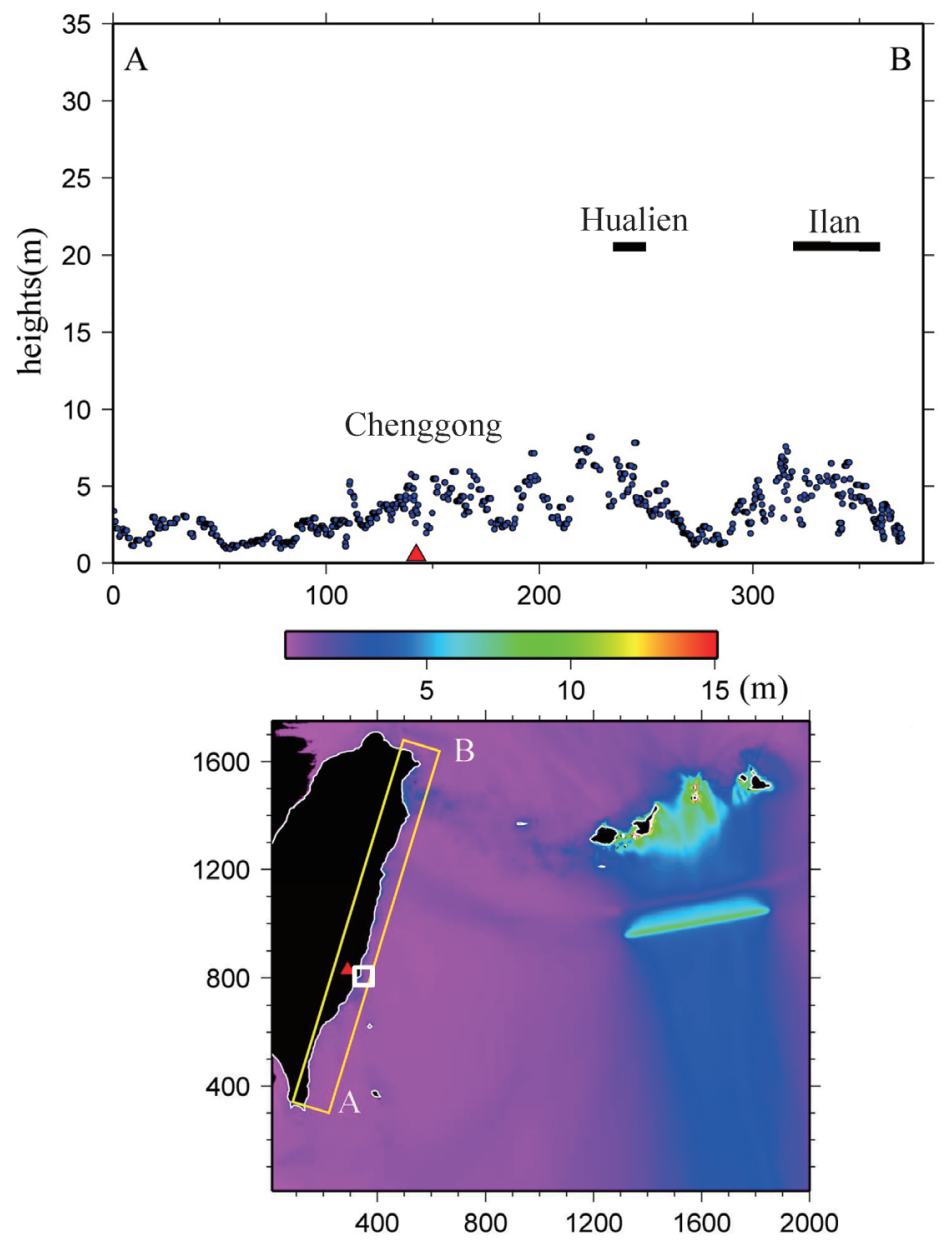

Fig. 7. The same as in Fig. 3, except for the tsunami in Model 3. High tsunami waves (>18 m) are seen around Ishigaki and Miyako Islands. The straight line off the coast of these islands indicates the large uplift corresponding to the upper edge of the fault plane. A relatively high tsunami is observed on the coast of Ilan (6 m), but the wave is lower on the coast of Chenggong (4 m). Model 3, which was constructed to fit the observations on Ishigaki and Miyako Islands (Nakamura 2009), cannot explain the Malaulau folklore.

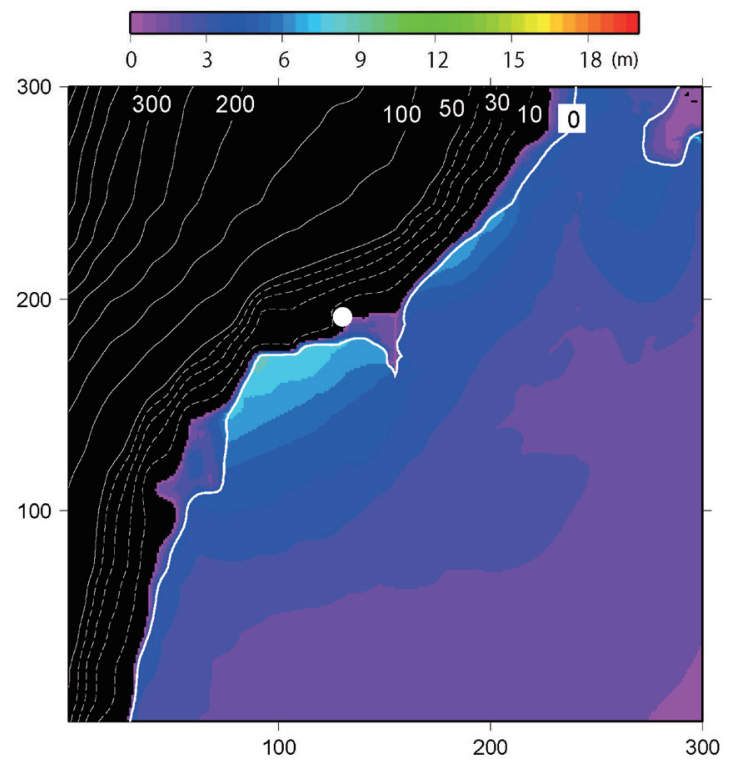

Fig. 8. The same as in Fig. 4a, except for the tsunami in Model 3. The inundation height is less than 3 - 5 m and the Malaulau site (the white solid circle) is not covered by the tsunami. 
top). Noticeably, on Hualien, Ilan and elsewhere, the tsunami wave heights are as large as on the area south of Chenggong. Figure 4a shows the maximum heights for Area 2, where the dispersion effect is taken into account in the calculation. The results are similar to the non-dispersive case shown in Fig. 4b. In the dispersive case, the shallow seas accompanying bathymetric highs near the coast of Chenggong with depths of mostly shallower than $20 \mathrm{~m}$ are somewhat effective in reducing the tsunami amplitudes. These results suggest that tsunami waves particularly around Chenggong are not more amplified than in other areas.

If Model 1 were an ordinary earthquake with seismic waves proportional to its seismic moment (Table 1), its strong ground motion would have been felt throughout Taiwan, with particularly strong shaking in northern Taiwan. However, no corresponding event was recorded in any historical documents in Taiwan around this time. In the $19^{\text {th }}$ century, such an event should have been recorded because the western half of Taiwan was populated at this time.

One possibility is that the event was a tsunami (slow) earthquake, because Model 1 is located on the up-dip of the slab interface shallower than $12 \mathrm{~km}$ (Hsu et al. 2012) and all tsunami earthquakes have occurred near subduction zone trenches (e.g., Satake and Tanioka 1999; Lay et al. 2011), similar to in Model 1. These shallow subduction zone earthquakes possibly related low rigidity materials along shallow slab interfaces in subduction zones (Bilek and Lay 1999). If Model 1 had been a tsunami earthquake, its strong motion may not have been recorded in the western half of Taiwan, and the tsunami may have struck the eastern half of Taiwan.

However, even if the earthquake was a tsunami (slow) earthquake, Model 1 cannot be accepted because tsunami heights should have reached 5 to $15 \mathrm{~m}$ on Ishigaki and Miyako Islands. If such high waves struck the islands, this event should have been recorded as written history, because the detail of fatalities and property losses from the 1771 tsunami were well documented on these islands (e.g., Imamura 1938; Makino 1968; Nakata and Kawana 1995; Goto et al. 2010). It is unlikely that such a big tsunami like Model 1 would be left unrecorded. In addition, if a tsunami reached $25 \mathrm{~m}$ on the coast of Ilan would have flooded into the Ilan plain. In 1810, the Kamaran, one of the Taiwanese aboriginal tribes in Ilan, had a population more than 8000 (Shimizu 2011). They could have recorded this event as oral history if it really occurred in this region. Consequently, we remove Model 1 as a possible candidate for the Malaulau event.

\subsection{Model 2}

Figure 5 shows the maximum height of a tsunami for Model 2, in which the fault plane is $30 \mathrm{~km}$ off the coast of Chenggong, and Fig. 6 includes dispersive effects, as in Model 1 . The tsunami amplitudes generated by this fault are high around Chenggong because of the proximity to the tsunami source. However, the amplitudes are not significantly larger on the coast of Chenggong than its surroundings. The tsunami height is $5-12 \mathrm{~m}$ on the coast of Ilan, $10-12 \mathrm{~m}$ on Hualien, 6 to $20 \mathrm{~m}$ on Lu Island and 2 to $12 \mathrm{~m}$ on Lanyu Island. The tsunami waves are amplified on the coasts around Ilan, which is mainly caused by the shallow bathymetric highs.

Model 2 can generate a large tsunami more effectively on the east coast near Chenggong because the elongated tsunami source is located close to and parallel to the coast of Chenggong. The back-thrust lies in the tertiary sedimentary wedge is much stronger than the near-trench sedimentary wedges (Lin et al. 2009) and possibly generate ordinary earthquakes. However, the same problem arises regarding historical records; if the earthquake was an ordinary earthquake, it should have been recorded in historical documents pertaining to the western half of Taiwan. If the earthquake was a tsunami (slow) earthquake or smaller with a submarine landslide as will be noted later, it would have been unrecorded in historical documents. Nevertheless, the tsunami might possibly have been recorded elsewhere around Chenggong or Lu and Lanyu Islands as tsunami deposits. Further investigation of Holocene layers on the coast is necessary to find evidence for plaeo-tsunamis on these areas.

\subsection{Model 3}

Figure 7 shows tsunami heights for the source model of the 1771 Yaeyama tsunami (Nakamura 2009), which is based on historical documents. Most tsunami energy is radiated to the NNW and SSW directions. The waves radiated from an elongated source are constructively enhanced for angles $0^{\circ}<\theta<45^{\circ}$ but they decrease with increasing angles for $\theta>45^{\circ}$, in which $\theta$ is the angle between the minor axis of the elliptical source and the direction from the center of the source to the observation point (Kajiura 1970). The tsunami was extraordinarily large, with a maximum runup height of $30 \mathrm{~m}$ on Ishigaki Island and $18 \mathrm{~m}$ on Miyako Island (Kato and Kimura 1983; Nakata and Kawana 1995; Nakamura 2009; Goto et al. 2010).

The calculated tsunami reaches heights of $3-8 \mathrm{~m}$ on the eastern coast of Taiwan (Fig. 7) and with maximum heights of 2 - $3 \mathrm{~m}$ on Lanyu and Lu Islands. If the tsunami amplitude was $15 \mathrm{~m}$ on the coast of Chenggong, the fault slip must have been three times larger than the slip estimated by Nakamura (2009). This assumption fails to fit the 1771 tsunami heights on Ishigaki and Miyako Islands. This model cannot explain both the story of Malaulau and the 1771 Yaeyama tsunami. Therefore, Model 3 can be excluded for explaining the Malualau tsunami.

\subsection{Other possibilities}

Another possible model is a tsunami caused by thrusting along the Manila trench (Megawati et al. 2009; Wu et al 
2009; Okal et al. 2011). However, this tsunami would mostly affect the southwest coast of Taiwan. There is no record of a tsunami in the $19^{\text {th }}$ century in the area. If the Malaulau story occurred in the late $18^{\text {th }}$ century, it can be related to the 1781 tsunami that was recorded in historical documents ( $\mathrm{Yu}$ 1981; Hsu and Lee 1996; Mak and Chan 2007; Lau et al. 2010). However, the tsunami amplitude caused by a Manila trench earthquake is small along most of the eastern coast of Taiwan, except Ilan (Wu et al. 2009). We exclude the possibility of a Manila trench event for the Malaulau case.

A tsunami caused by a local small submarine slope failure near Chenggong, similar to the 1998 Papua New Guinea tsunami and the 2010 event in the Cook Islands, is another possible explanation for the Malaulau story. The 1998 tsunami was caused by large underwater landslides triggered by an $M_{w} 7.0$ earthquake in the northern coast region of Papua New Guinea. This tsunami struck the coast with a run-up of $5-15 \mathrm{~m}$ a. s. 1., and killed approximately 2100 people (Synolakis et al. 2002). The 2010 event caused an unrecorded local tsunami that struck an uninhabited area with a maximum inundation of $100 \mathrm{~m}$ inland and a run-up of $12 \mathrm{~m}$ a. s. 1. (Goff 2011). If a local submarine landslide happened off the coast of Chenggong, it should have been unfelt in the western half of the Taiwan and not have been recorded. However, little evidence of detailed seafloor topography is available that could cause a local submarine failure near the coast of Chenggong. Further detailed bathymetric surveys are necessary to resolve this issue.

\subsection{The reliability of folklore}

The reliability of the story of Malaulau is uncertain because it is only available in Chenggong. During our study, we met a lady in her forties who has roots in the Ami tribe near Hualien for more than 100 years. She said that her grandmother's father told her grandmother about a tsunami near Hualien and that she heard the story from her grandmother many times. There are a number of similar oral legends from Taiwanese aborigine tribes, such as the Ami, Yami and Passo, describing large sea waves striking land (Sayama and Onishi 1923; Asai and Ogawa 1935). However, It is unknown if these legends relate in fact tsunamis caused by offshore faulting or submarine slope failures. Further study of the folklore of tsunamis on the eastern coast of Taiwan is necessary.

\section{SUMMARY}

According to folklore, a high sea wave struck the Pacific coast of Chenggong on the eastern coast of Taiwan. Because the site is $18 \mathrm{~m}$ a. s. 1 . and $400 \mathrm{~m}$ inland from the coast, the wave is thought to have been a tsunami. This event may have happened in the middle of the $19^{\text {th }}$ century. However, there is no record of such a tsunami outside of Cheng- gong. Numerical simulations were carried out on the basis of three tsunami source models, which are located (1) in the westernmost portion of the Ryukyu trench, (2) offshore of Chenggong, and (3) at the source of the 1771 Yaeyama tsunami along the Ryukyu trench. Model 1 produces too large tsunami amplitudes on the islands of Ishigaki and Miyako, which is inconsistent with the written history on the islands. Model 3 generates too small tsunami heights on the western coast of Taiwan to explain the Malaulau folklore. We excluded these two models for the Malaulau event. On the other hand, Model 2 fits to the tsunami heights along the eastern coast of Taiwan, particularly around Chenggong. However, it is still inconsistent with the written history recorded in the western half of Taiwan where it was already populated in the middle of the $19^{\text {th }}$ century. This model is also excluded for the Malaulau model. If a local submarine slide occurred off Chenggong, a limited area should have been struck by tsunami amplitudes. However, little evidence of detailed bathymetric data supporting submarine landslides is available. Considering the tsunami waves are not significantly amplified around Chenggong, other places on the eastern coast of Taiwan should have been affected by the Malaulau tsunami if it did occur. Further studies of geological tsunami deposits, the submarine topography, and folklore of Taiwanese aboriginal tribes are required for the investigation of the tsunami source and size to understand the future tsunami risk on the eastern cost of Taiwan.

Acknowledgements We acknowledge two anonymous reviewers for their constructive comments and suggestions, which significantly improved the revised manuscript. We thank Mr. He-Sheng Wang for providing details on the folklore of Malaulau; Ceng-Sheng Yuan, Yoko Ota, Nobuhisa Matta, and Wenji Lai for valuable information and discussions on the tsunamis in Taiwan; and Yoko Tu for preparing the bathymetric datasets and drawing figures. We used data provided by the Ocean Data Bank, ETOPO 1 and the Center for Space and Remote Sensing Research (NCU), and the software GMT. This work was funded by the National Science Council, Taiwan, Project No. NSC 101-2116-M-001-025.

\section{REFERENCES}

Abe, Y., 1938: The Research of Locality Names in Taiwan, Sugita Publication, Tokyo, 300 pp. (in Japanese)

Asai, E. and N. Ogawa, 1935: The Myths and Traditions of the Formosan Native Tribes: Texts and Notes, Toko Shoin, Tokyo, 783 pp. (in Japanese)

Bilek, S. L. and T. Lay, 1999: Rigidity variations with depth along interplate megathrust faults in subduction zones. Nature, 400, 443-446, doi: 10.1038/22739. [Link]

Blanchet, R., J. Angelier, and C. S. Ho, 1986: Geodynamics of the Eurasia-Philippine Sea plate boundary. Tectonophysics, 125, 1-285. 
Cheng, S. N. and Y. T. Yeh, 1989: Catalog of the Earthquakes in Taiwan from 1604 to 1988, Institute of Earth Sciences, Academia Sinica, 255 pp.

Chi, W. C. and D. L. Reed, 2008: Evolution of shallow, crustal thermal structure from subduction to collision: An example from Taiwan. Geol. Soc. Am. Bull., 120, 679-690, doi: 10.1130/B26210.1. [Link]

Davis, D., J. Suppe, and F. A. Dahlen, 1983: Mechanics of fold-and-thrust belts and accretionary wedges. J. Geophys. Res., 88, 1153-1172, doi: 10.1029/ JB088iB02p01153. [Link]

Goff, J., 2011: Evidence of a previously unrecorded local tsunami, 13 April 2010, Cook Islands: Implications for Pacific Island countries. Nat. Hazards Earth Syst. Sci., 11, 1371-1379, doi: 10.5194/nhess-11-1371-2011. [Link]

Goto, K., T. Kawana, and F. Imamura, 2010: Historical and geological evidence of boulders deposited by tsunamis, southern Ryukyu Islands, Japan. Earth-Sci. Rev., 102, 77-99, doi: 10.1016/j.earscirev.2010.06.005. [Link]

Hsu, M. T., 1983: Estimation of earthquake magnitudes and seismic intensities of destructive earthquakes in the Ming and Ching Eras. Meteorol. Bull. CWB, ROC, 29, 1-18. (in Chinese)

Hsu, M. K. and Q. Lee, 1996: Tsunami in the region near Taiwan. Acta Oceanogr. Taiwan., 35, 1-16. (in Chinese)

Hsu, Y. J., S. B. Yu, M. Simons, L. C. Kuo, and H. Y. Chen, 2009: Interseismic crustal deformation in the Taiwan plate boundary zone revealed by GPS observations, seismicity, and earthquake focal mechanisms. Tectonophysics, 479, 4-18, doi: 10.1016/j.tecto.2008.11.016. [Link]

Hsu, Y. J., M. Ando, S. B. Yu, and M. Simons, 2012: The potential for a great earthquake along the southernmost Ryukyu subduction zone. Geophys. Res. Lett., 39, L14302, doi: 10.1029/2012GL052764. [Link]

Imamura, A., 1938: Seismicities at Ryukyu Islands and the Meiwa Tsunami. J. Seismol. Soc. Jpn., 10, 431-442. (in Japanese)

Kajiura, K., 1970: Tsunami energy in relation to parameters of the earthquake fault model. Bull. Earthquake Res. Inst., Tokyo Univ., 56, 415-440.

Kato, Y. and M. Kimura, 1983: Age and origin of so-called "Tsunami-ishi", Ishigaki Island, Okinawa prefecture. J. Geol. Soc. Jpn., 89, 471-474. (in Japanese with English abstract)

Lay, T., C. J. Ammon, H. Kanamori, Y. Yamazaki, K. F. Cheung, and A. R. Hutko, 2011: The 25 October 2010 Mentawai tsunami earthquake $\left(\mathrm{M}_{\mathrm{w}}\right.$ 7.8) and the tsunami hazard presented by shallow megathrust ruptures. Geophys. Res. Lett., 38, L06302, doi: 10.1029/2010GL046552. [Link]

Lau, A. Y. A., A. D. Switzer, D. Dominey-Howes, J. C. Aitchison, and Y. Zong, 2010: Written records of historical tsunamis in the northeastern South China Sea - challenges associated with developing a new integrated database. Nat. Hazards Earth Syst. Sci., 10, 1793-1806, doi: 10.5194/nhess-10-1793-2010. [Link]

Lin, A. T., B. Yao, S. K. Hsu, C. S. Liu, and C. Y. Huang, 2009: Tectonic features of the incipient arc-continent collision zone of Taiwan: Implications for seismicity. Tectonophysics, 479, 28-42, doi: 10.1016/j.tecto.2008.11.004. [Link]

Lin, C. H., 2000: Thermal modeling of continental subduction and exhumation constrained by heat flow and seismicity in Taiwan. Tectonophysics, 324, 189-201, doi: 10.1016/S0040-1951(00)00117-7. [Link]

Lundberg, N., D. L. Reed, C. S. Liu, and J. Lieske Jr., 1997: Forearc-basin closure and arc accretion in the submarine suture zone south of Taiwan. Tectonophysics, 274, 5-23, doi: 10.1016/S0040-1951(96)00295-8. [Link]

Ma, K. F. and M. F. Lee, 1997: Simulation of historical tsunamis in the Taiwan region. Terr. Atmos. Ocean. Sci., 8, 13-30.

Mak, S. and L. S. Chan, 2007: Historical tsunamis in South China. Nat. Hazards, 43, 147-164, doi: 10.1007/ s11069-007-9113-6. [Link]

Makino, K., 1968: The Meiwa Tsunami in Yaeyama, published privately by the author, Okinawa, $462 \mathrm{pp}$. (in Japanese)

Mansinha, L. and D. E. Smylie, 1971: The displacement fields of inclined faults. Bull. Seismol. Soc. Am., 61, 1433-1440.

Matta, N., Y. Ota, M. Ando, N. Nishikawa, A. Switzer, T. Haraguchi, and C. H. Lin, 2013a: Possible paleotsunami at Chenggong coast, eastern Taiwan, as deduced from the excavation of Holocene sediments, submitted to Journal of Asian Earth Sciences.

Matta, N., Y. Ota, W. S. Chen, Y. Nishikawa, M. Ando, and L. H. Chung, 2013b: Finding of probable tsunami boulders on Jiupeng coast in southeastern Taiwan. Terr. Atmos. Ocean. Sci., 24, 159-163, doi: 10.3319/ TAO.2012.09.14.01(TT). [Link]

Megawati, K., F. Shaw, K. Sieh, Z. Huang, T. R. Wu, Y. Lin, S. K. Tan, and T. C. Pan, 2009: Tsunami hazard from the subduction megathrust of the South China Sea: Part I. source characterization and the resulting tsunami. J. Asian Earth Sci., 36, 13-20, doi: 10.1016/j. jseaes.2008.11.012. [Link]

Mori, N., T. Takahashi, T. Yasuda, and H. Yanagisawa, 2011: Survey of 2011 Tohoku earthquake tsunami inundation and run-up. Geophys. Res. Lett., 38, L00G14, doi: 10.1029/2011GL049210. [Link]

Nakamura, M., 2006: Source fault model of the 1771 Yaeyama tsunami, southern Ryukyu Islands, Japan, inferred from numerical simulation. Pure Appl. Geophys., 163, 41-54, doi: 10.1007/s00024-005-0007-9. [Link]

Nakamura, M., 2009: Fault model of the 1771 Yaeyama earthquake along the Ryukyu Trench estimated from 
the devastating tsunami. Geophys. Res. Lett., 36, L19307, doi: 10.1029/2009GL039730. [Link]

Nakata, T. and T. Kawana, 1995: Historical and prehistorical large tsunamis in the southern Ryukyus, Japan. In: Tsuchia, Y., and N. Shuto (Eds.), Tsunami: Progress in Predication, Disaster Prevention and Warning, Kluwer Academic Publishers, Dordrecht, Netherlands, 211-222.

Ng, S. M., J. Angelier, and C. P. Chang, 2009: Earthquake cycle in Western Taiwan: Insights from historical seismicity. Geophys. J. Int., 178, 753-774, doi: 10.1111/j.1365-246X.2009.04164.x. [Link]

Okal, E. A., C. E. Synolakis, and N. Kalligeris, 2011: Tsunami Simulations for regional sources in the South China and adjoining Seas. Pure Appl. Geophys., 168, 1153-1173, doi: 10.1007/s00024-010-0230-x. [Link]

Satake, K. and Y. Tanioka, 1999: Sources of tsunami and tsunamigenic earthquakes in subduction zones. Pure Appl. Geophys., 154, 467- 483, doi: 10.1007/ s000240050240. [Link]

Sayama, Y. and Y. Ohnishi, 1923: Legends of the Taiwanese Aborigines, Sugita Jyuzo Press, 782 pp. (in Japanese)

Shimizu, J., 2011: The Kamaran Tribe: A Changing People, The Institute of Ethnology, Academia Sinica, 357 pp. (in Chinese)

Shyu, J. B. H., K. Sieh, Y. G. Chen, and C. S. Liu, 2005: Neotectonic architecture of Taiwan and its implications for future large earthquakes. J. Geophys. Res., 110, B08402, doi: 10.1029/2004JB003251. [Link]

Suppe, J., 1981: Mechanics of mountain building and metamorphism in Taiwan. Mem. Geol. Soc. China, 4, 67-89.

Synolakis, C. E., J. P. Bardet, J. C. Borrero, H. L. Davies, E. A. Okal, E. A. Silver, S. Sweet, and D. R. Tappin, 2002: The slump origin of the 1998 Papua New Guinea tsunami. Proc. R. Soc. Lond. A, 458, 763-789, doi: 10.1098/rspa.2001.0915. [Link]

Wu, F. T., W. T. Liang, J. C. Lee, H. Benz, and A. Villasenor, 2009: A model for the termination of the Ryukyu subduction zone against Taiwan: A junction of collision, subduction/separation, and subduction boundaries. J. Geophys. Res., 114, B07404, doi: 10.1029/2008JB005950. [Link]

Wu, T. R. and H. C. Huang, 2009: Modeling tsunami hazards from Manila trench to Taiwan. J. Asian Earth Sci., 36, 21-28, doi: 10.1016/j.jseaes.2008.12.006. [Link]

Yamaguchi, M. and Y. Ota, 2002: Tectonic and Paleoseismological significance of Holocene marine terraces on the east coast of Coastal Range, Taiwan. J. Geogr., 111, 323-340. (in Japanese with English abstract and figure captions)

Yu, S. B., 1981: Destructive earthquake tsunamis in the Ming and Ching eras. Meteorology, 40, 37-46. (in Chinese)

Yu, S. B., H. Y. Chen, and L. C. Kuo, 1997: Velocity field of GPS stations in the Taiwan area. Tectonophysics, 274, 41-59, doi: 10.1016/S0040-1951(96)00297-1. [Link]

\section{APPENDIX}

The equations used in this study are summarized below.

We assume that $x$ and $y$ are the horizontal coordinates, $\eta$ is the water-surface elevation, $D=\eta+h$ is the total water depth, $h$ is the still water depth, $Q_{x}$ and $Q_{y}$ are the discharge fluxes in the $x$ and $y$ directions, respectively, $g$ is the gravitational acceleration and $t$ is time.

For Area 1, nonlinear long wave equations are used as follows:

$$
\begin{aligned}
& \frac{\partial \eta}{\partial t}+\frac{\partial Q_{x}}{\partial x}+\frac{\partial Q_{y}}{\partial y}=0 \\
& \frac{\partial Q_{x}}{\partial t}+\frac{\partial}{\partial x}\left[\frac{Q_{x}^{2}}{D}\right]+\frac{\partial}{\partial y}\left[\frac{Q_{x} Q_{y}}{D}\right]+g D \frac{\partial \eta}{\partial x}+M_{x}=0 \\
& \frac{\partial Q_{y}}{\partial t}+\frac{\partial}{\partial y}\left[\frac{Q_{y}^{2}}{D}\right]+\frac{\partial}{\partial x}\left[\frac{Q_{x} Q_{y}}{D}\right]+g D \frac{\partial \eta}{\partial y}+M_{y}=0
\end{aligned}
$$

The bottom friction comes from Manning' formula and is expressed as:

$$
\begin{aligned}
& M_{x}=\frac{g n^{2}}{D^{7 / 3}} Q_{x}\left(Q_{x}^{2}+Q_{y}^{2}\right)^{1 / 2} \\
& M_{y}=\frac{g n^{2}}{D^{7 / 3}} Q_{y}\left(Q_{x}^{2}+Q_{y}^{2}\right)^{1 / 2}
\end{aligned}
$$

where $Q_{x}$ and $Q_{y}$ are the bottom frictions and $n$ is the Manning coefficient. In this calculation, $n=0.025$ for the nearshore ocean bottom coefficient.

For Area 2, dispersive long wave equations are used as follows:

$$
\begin{aligned}
& \frac{\partial \eta}{\partial t}+\frac{\partial Q_{x}}{\partial x}+\frac{\partial Q_{y}}{\partial y}=0 \\
& \frac{\partial Q_{x}}{\partial t}+\frac{\partial}{\partial x}\left[\frac{Q_{x}^{2}}{D}\right]+\frac{\partial}{\partial y}\left[\frac{Q_{x} Q_{y}}{D}\right]+g D \frac{\partial \eta}{\partial x}+M_{x} \\
& =\frac{2}{5} h^{2}\left(\frac{\partial^{3} Q_{x}}{\partial t \partial x^{2}}+\frac{\partial^{3} Q_{y}}{\partial t \partial x \partial y}\right)+\frac{1}{15} g h^{3}\left(\frac{\partial^{2} \eta}{\partial x^{3}}+\frac{\partial^{2} \eta}{\partial x \partial y^{2}}\right) \\
& \frac{\partial Q_{y}}{\partial t}+\frac{\partial}{\partial y}\left[\frac{Q_{y}^{2}}{D}\right]+\frac{\partial}{\partial x}\left[\frac{Q_{x} Q_{y}}{D}\right]+g D \frac{\partial \eta}{\partial y}+M_{y} \\
& =\frac{2}{5} h^{2}\left(\frac{\partial^{3} Q_{y}}{\partial t \partial y^{2}}+\frac{\partial^{3} Q_{x}}{\partial t \partial x \partial y}\right)+\frac{1}{15} g h^{3}\left(\frac{\partial^{2} \eta}{\partial y^{3}}+\frac{\partial^{2} \eta}{\partial y \partial x^{2}}\right)
\end{aligned}
$$

In this case, wave dispersion is involved in the right-hand sides of Area 2 because dispersion can play an important role at the wide shallow slopes in Area 2.

The radiation open boundary condition is adopted to allow wave propagation away from the numerical domain:

$$
\begin{aligned}
& \frac{\partial \eta}{\partial t}+\sqrt{g h} \frac{\partial \eta}{\partial x}=0 \\
& \frac{\partial \eta}{\partial t}+\sqrt{g h} \frac{\partial \eta}{\partial y}=0
\end{aligned}
$$

